\title{
REIMBURSED COSTS OF MANAGEMENT OF UTERINE CERVICAL LESIONS IN POLAND - A DESCRIPTIVE ANALYSIS OF DATA FROM THE NATIONAL HEALTH FUND AND THE MINISTRY OF HEALTH
}

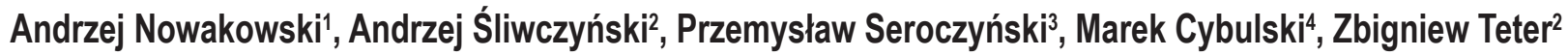 \\ 'Second Department Oncologic Gynaecology, Saint John of Dukla Regional Cancer Centre, Lublin, Poland \\ ${ }^{2}$ Central Office, National Health Fund, Warsaw, Poland \\ ${ }^{3}$ ASSECO S.A. Poland, Warsaw, Poland \\ ${ }^{4}$ Department of Biochemistry and Molecular Biology, Medical University of Lublin, Lublin, Poland
}

\section{SUMMARY}

Background: Despite implementation of organised screening programme in 2006/2007, cervical cancer (CC) incidence and mortality in Poland are still higher than the average in the European Union. CC and preceding cervical intraepithelial neoplasia (CIN) caused by human papillomaviruses (HPVs) can be prevented by vaccines which are reimbursed in around 20 European countries but not in Poland. CC and CIN can be also detected with the use of HPV tests which are not included in the Polish screening programme. Reimbursement for HPV vaccines and HPV testing requires cost-effectiveness analyses which include country-specific data on the burden and costs of management of cervical neoplasia. Therefore, we investigated the burden of cervical neoplasia and direct costs associated with its detection and management in Poland in 2012 reimbursed by the National Health Fund (NHF) - the only public healthcare insurance institution. We also report administrative costs of the organised screening programme covered by the Ministry of Health.

Methods: Data on the burden and reimbursed costs of organised and opportunistic screening as well as management of cervical neoplasia were drawn from the NHF databases. Numbers of women reported with CIN and CC were ascertained.

Results: In 2012, there were 765,266 and 1,288,358 reimbursed Pap smears collected within and outside the organised screening programme, respectively. Expenditures on medical and administrative procedures in organised screening reached PLN (Polish Zloty) 41,470,664 and 12,150,398 respectively. The number of women with particular diagnosis and reimbursement for the management of these lesions were as follows: glandular ectropion 208,033 and PLN 37,349,515; CIN1 10,521 and PLN 6,616,375; CIN2 5,812 and PLN 5,071,155; CIN3 6,487 and PLN 7,611,062; unspecified grade CIN 36,575 and PLN 12,352,034; and CC 33,482 and PLN 52,377,006, respectively. In women with ectropion and CIN the total number of local excision/ablative therapeutic procedures on the cervix reached 47,658 and the total number of hysterectomies was 1,321.

Conclusion: In 2012, management of approximately 93 thousand women with HPV-related cervical lesions reimbursed in Poland amounted to PLN 84,027,632 which makes it a considerable public health problem. The number of women managed for glandular ectropion is considerable and related costs are high. Total reimbursement for detection, treatment and follow-up of all cervical lesions reaches at least PLN 137 million annually.

Key words: cervical cancer, cervical intraepithelial neoplasia, screening, costs, reimbursement, Poland

Address for correspondence: A. Nowakowski, Second Department Oncologic Gynaecology, Saint John of Dukla Regional Cancer Centre, Jaczewskiego 7, 20-090 Lublin, Poland. E-mail: andrzejmnowakowski@poczta.onet.pl

http://dx.doi.org/10.21101/cejph.a4737

\section{INTRODUCTION}

Cervical cancer (CC) is a major public health problem worldwide as the fourth most common malignant neoplasm in women with approximately 528,000 new cases and 266,000 deaths estimated for 2012 (1). It has been proven that infection with human papillomavirus (HPV) is a necessary cause of CC and a great majority of its precursors termed CIN (cervical intraepithelial neoplasia graded 1, 2 and 3) (2). Prophylactic vaccines against HPVs are currently registered and available worldwide. They are reimbursed in about 40 countries, including around 20 in Europe (3). They have been proven to be safe, immunogenic and highly effective in clinical trials (4). The fact that HPV is an aetiological factor of CC and CIN has been also utilized in elaborating HPV assays applied as sensitive screening tests to detect CIN and CC (5) and HPV tests are currently in clinical use in many parts of the world.

Population of Poland is 38.5 million inhabitants and CC agestandardised mortality rate of 7.4/100,000 is twice as high as the average 3.7/100,000 in European Union (6) and is decreasing slowly (7) despite initiation of organised screening in 2006/2007. 
Although recommended for use in immunization programme by the Ministry of Health (8), HPV vaccines are not reimbursed from public funds for general population of adolescent girls. HPV tests are currently used in pilot studies in organised screening programme in two regions of Poland but are not reimbursed for screening in the country.

Country-specific data on the burden and costs of management of HPV-related cervical neoplasia are important for public health decision-makers and may be used to plan public health interventions or for health technology assessment analyses of new technologies in screening and vaccination. Pharmacoeconomic modelling proved various degrees of HPV vaccination costeffectiveness for many countries (9-12) and it was used to make decisions on their reimbursement. Also, HPV testing has proven to be cost-effective in many countries (13) but such analyses for Poland have not been performed yet.

The National Cancer Registry in Poland produces data on incidence of and mortality from invasive cancers, but the burden of precancerous lesions and comprehensive costs of management of cervical neoplasia in Poland, to our knowledge, have not been analysed and published yet. Therefore, the objective of our study was to estimate the burden of cervical neoplasia and costs of its detection and management in Poland from the perspective of the National Health Fund (NHF) - the only public healthcare insurance institution. These data may turn out to be important for further analysis of cost-effectiveness of HPV-based screening and $\mathrm{HPV}$ vaccination in the prevention of CIN and CC.

\section{MATERIALS AND METHODS}

\section{Burden and Costs of Medical Procedures in Organ- ised and Opportunistic CC Screening}

The costs of medical procedures in organised and opportunistic screening are covered by the NHF. Approximately 95\% of the Polish population are insured in the NHF and this analysis tends to present data from the national health-payer's perspective. All data on the numbers of medical procedures and related costs of organised CC screening in Poland in 2012 were drawn from cervical screening registry called the Information System for Monitoring of Prophylaxis (ISMP). Data on the reimbursed opportunistic screening were drawn from other NHF electronic databases by drawing the numbers and related costs of reimbursement of services coded with the International Classification of Diseases version 10 (ICD10) code Z12.4 (special screening examination for neoplasm of the cervix). To produce a more comprehensive picture of the burden of reimbursed Pap tests, the data on Pap tests performed within NHF-reimbursed services were also drawn by the number of services reported with the International Classification System for Surgical, Diagnostic and Therapeutic Procedures (ICD-9-CM) code: 91.447 (microscopic examination of specimen from female genital tract - cytology from cervix). All costs are presented in Polish currency (PLN - Polish Zloty).

\section{Administrative Costs of Organised Screening}

Administrative and logistic costs of organised CC cancer screening programme are covered by the Ministry of Health from funds of the National Programme for Control of Cancerous Diseases Act - a parliament bill (14). Total administrative costs of execution of both breast and CC screening programmes in 2012 were published as a part of parliamentary report (15). Total costs of generation, printing and postage of written invitations for mammography and cytology were subtracted from the total sum spent for the administrative execution of both screening programmes and $50 \%$ of the remaining sum was estimated to be spent for cervical screening since most of regional coordinating offices manage both screening programmes together. These costs include quality control and actions to increase coverage. Costs of generation, printing and postage of invitations for cytology were calculated separately by multiplying the number of sent invitations (based on data from ISMP) by the unit cost established by the Ministry of Health.

\section{Burden of Cervical Lesions and Costs of Their Man- agement}

Number of women with CIN managed in 2012 in Poland was calculated based on the reports on ambulatory and hospital services reimbursed by the NHF. Data on patients with services coded with adequate ICD10 codes were drawn from the NHF database. The following codes were used to produce numbers of cases of cervical lesions and related costs of their management: N87.0 (mild cervical dysplasia) - CIN1, N87.1 (moderate cervical dysplasia) - CIN2. Records with codes: D06 (carcinoma in situ of cervix uteri), D06.0 (carcinoma in situ of endocervix), D06.1 (carcinoma in situ of exocervix), D06.7 (carcinoma in situ of other parts of the cervix), D06.9 (carcinoma in situ of the unspecified part of the cervix) and N87.2 (severe cervical dysplasia) were combined and classified as CIN3 cases. Carcinoma in situ has been deleted from classification of the International Federation of Obstetrics and Gynaecology (16) and is currently classified together with CIN3 as one entity. The number of cases of unspecified grade CIN was calculated by combining cases with codes N87 (dysplasia of the cervix) and N87.9 (dysplasia of the cervix uteri, unspecified). Diagnosis of cervical glandular ectropion/erosion is very common in Poland and misdiagnosis with true cervical neoplasia and vice versa is very likely since ectropion is still erroneously considered as precancerous lesion by many clinicians. Therefore, to present a comprehensive picture on the burden and costs of treatment of cervical lesions we have also drawn data on the number of cases and direct costs of treatment of glandular ectropion/erosion in Poland in 2012. We used ICD10 code N86 (cervical glandular ectropion/erosion) to obtain these data. We tracked ICD-9-CM codes to present data on therapeutic procedures (local cervical excisional/ablative procedures and hysterectomies) and all other medical procedures performed in women diagnosed cervical lesions.

\section{Burden of Services for Invasive Cervical Cancer and Their Costs}

Data on the number of women reported with diagnoses of invasive CC in 2012 and costs related with their management were based on the reported cases and reimbursement of ambulatory and hospital services provided within NHF for patients coded with the following ICD10 codes: C53 (malignant neoplasm of cervix uteri), C53.0 (malignant neoplasm of endocervix), C53.1 (malignant neoplasm of exocervix), C53.8 (overlapping malignant lesion of 
the cervix) and C53.9 (malignant neoplasm of cervix uteri, unspecified). To present a more specific view on the types and costs of management, the ICD-9-CM procedures were classified into the following six groups: diagnostic imaging examinations; surgical and conservative treatment in gynaecological, surgical, urological and intensive care units; teleradiotherapy/brachytherapy and related hospitalization; chemotherapy and related hospitalisation; rehabilitation; and long-term and palliative care.

\section{RESULTS}

\section{Burden and Costs of Medical Procedures in Organ- ised and Opportunistic CC Screening}

The numbers of Pap smears collected and evaluated as well as the numbers of colposcopies and colposcopies with directed biopsies performed in organised screening are presented in Table 1. Additionally, the number of CC screening services and their related reimbursement costs in opportunistic screening are presented in Table 2. The total costs of medical procedures in organised CC screening in 2012 amounted to PLN 41,470,664.

\section{Administrative Costs of Organised Cervical Screen- ing in 2012}

The total costs of administration of organised breast and cervical cancer screening equalled PLN 21,793,882 in 2012. Of these, PLN $8,692,605$ were spent for generation, printing and postage of invitations for mammography and cytology. $50 \%$ of the remaining sum is PLN 6,550,639 which is an estimated amount spent for the administrative and logistic costs of the CC programme in 2012 in Poland. There were 3,293,976 personal invitations sent for a Pap smear in 2012 at PLN 1.7 unit cost and their total cost was PLN 5,599,759. The total costs of administration of the organised screening programme in 2012 in Poland were therefore estimated at PLN 12,150,398.

\section{Burden of Cervical Lesions and Costs of Their Man- agement}

The numbers of cases managed for cervical glandular ectropion, cervical intraepithelial neoplasia of different grades are presented in Table 2. Total costs of diagnosis and treatment of cervical glandular ectropion/erosion were higher than those of treatment of all grades of CIN which equalled PLN 31,650,626. Numbers of local therapeutic ablative/excision cervical proce-

Table 1. Numbers of medical procedures and their costs in organised and opportunistic cervical cancer screening in Poland in 2012

\begin{tabular}{|l|c|c|c|c|c|}
\hline & \multicolumn{5}{|c|}{ Type of procedure } \\
\cline { 2 - 6 } & $\begin{array}{c}\text { Pap smears collected } \\
\text { in organised } \\
\text { screening }\end{array}$ & $\begin{array}{c}\text { Pap smears evalu- } \\
\text { ated in organised } \\
\text { screening }\end{array}$ & $\begin{array}{c}\text { Colposcopy in } \\
\text { organised screening }\end{array}$ & $\begin{array}{c}\text { Colposcopy with } \\
\text { directed biopsy in } \\
\text { organised screening }\end{array}$ & $\begin{array}{c}\text { NHF-Reimbursed op- } \\
\text { portunistic screening } \\
\text { procedures }\end{array}$ \\
\hline Numbers & 765,266 & 764,977 & 1,717 & 4,483 & 74,591 \\
\hline Unit cost in PLN & 26.22 & 26.4 & 73.57 & 241.73 & $58.78^{\mathrm{c}}$ \\
\hline Total costs in PLN & $20,065,275$ & $20,195,393$ & 126,320 & $1,083,676$ & $4,384,725$ \\
\hline
\end{tabular}

Data from the databases of the National Health Fund

alnclude only services coded with ICD10 code Z12.4 (special screening examination for neoplasm of the uterine cervix). The total number of Pap smears collected within NHF reimbursed services outside organized screening in 2012 was $1,288,358$. These include Pap smears used for triage of previous abnormal cytology, follow-up of women treated for CIN and cancer, opportunistic screening and other indications at the discretion of gynaecologists. These services were coded with various ICD10 codes.

$1,213,767$ of these Pap test were collected within services coded with ICD10 codes other than Z12.4 and therefore cannot be formally classified as "opportunistic screening"

Pap smears. These procedures are included into evaluated costs of the management of glandular ectropion/erosion, CIN and CC (Table 2).

${ }^{\mathrm{b}}$ Average unit cost in the country

${ }^{\mathrm{c}}$ Average unit cost of appointment at gynaecological office with a Pap smear collection and evaluation

Table 2. Numbers of women reported with cervical lesions in Poland, numbers of procedures and their reimbursed costs in 2012

\begin{tabular}{|c|c|c|c|c|c|}
\hline & \multicolumn{5}{|c|}{ Type of cervical lesion } \\
\hline & $\begin{array}{c}\text { Glandular } \\
\text { ectropion/erosion }\end{array}$ & CIN1 & CIN2 & $\begin{array}{l}\text { CIN3/carcinoma } \\
\text { in situ }\end{array}$ & CIN unspecified \\
\hline Number of women with the respective diagnosis & 208,033 & 10,521 & 5,812 & 6,487 & 36,575 \\
\hline Total number of all reported medical procedures ${ }^{a}$ & 530,089 & 29,520 & 18,436 & 21,641 & 40,535 \\
\hline $\begin{array}{l}\text { Total number of reported local therapeutic } \\
\text { procedures }^{b}\end{array}$ & 39,996 & 1,725 & 1,875 & 2,137 & 1,925 \\
\hline Total number of reported hysterectomies & 17 & 130 & 196 & 684 & 294 \\
\hline Ambulatory costs ${ }^{\mathrm{C}}$ & $20,869,985$ & 683,937 & 280,770 & 343,173 & $3,119,762$ \\
\hline Hospital costs ${ }^{c}$ & $16,479,530$ & $5,932,438$ & $4,790,386$ & $7,267,889$ & $9,232,272$ \\
\hline Total costs ${ }^{c}$ & $37,349,515$ & $6,616,375$ & $5,071,155$ & $7,611,062$ & $12,352,034$ \\
\hline
\end{tabular}

Data from the databases of the National Health Fund

anclude all types of medical procedures such as consultations, diagnostic tests, therapeutic procedures etc. reported with respective ICD-9-CM codes

'Include cryotherapy, diathermy, laser vaporisation, loop electrosurgical excision procedure (LEEP), large loop excision of the transformation zone (LLETZ), cold knife conisation, amputation of the uterine cervix

${ }^{\circ}$ Data presented in PLN 
dures and hysterectomies performed in women with benign and preinvasive cervical lesions are also presented in Table 2.

\section{Burden of Services for Invasive Cervical Cancer and Their Costs}

The number of CC cases treated in 2012 and reported to the NHF was 33,482 . The total NHF costs related to the management of patients with invasive cervical cancer in Poland in 2012 reached PLN 52,377,006. Specified cost groups of procedures are presented in Fig. 1. Teleradiotherapy/brachytherapy and associated hospitalisation costs were the highest and accounted for $39.0 \%$ of the total CC treatment costs. Surgical and conservative treatment in gynaecological, surgical, urological and intensive care units; long-term and palliative care; diagnostic imaging examinations; chemotherapy and related hospitalisation accounted for $37.3 \%, 13.9 \%, 7.9 \%$ and $1.8 \%$ of the total CC management costs, respectively. Only $0.1 \%$ of the total costs were spent for rehabilitation of women with CC in 2012 in Poland.

\section{DISCUSSION}

Data on the burden and related costs of management of certain diseases are crucial for planning and execution of effective public health interventions. In case of cervical cancer, new ways of prevention have become recently available - primary prevention through HPV vaccination and secondary prevention (screening) by HPV testing. However, population-based HPV vaccination of teenage girls and routine testing for HPV infection in organised cervical cancer screening are very costly and require analyses of their cost-effectiveness, especially in a country like Poland where resources for reimbursed immunisation programmes are very limited. Also, implementation of new screening methods such as HPV testing should be cost-effective in comparison to current practices based on relatively inexpensive exfoliative cytology.

Cost-effectiveness analyses of HPV vaccination and HPV testing require base data on the burden and related costs of detection and treatment of preinvasive and invasive cervical neoplasia.

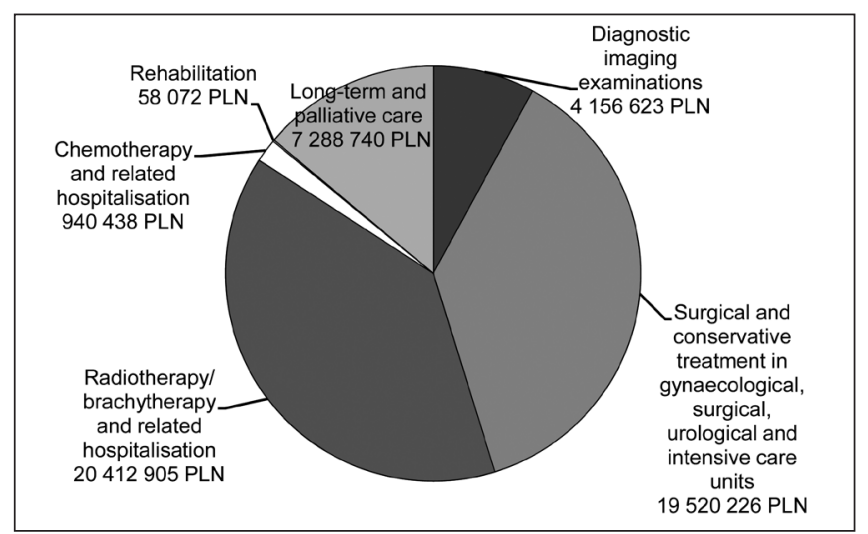

Fig. 1. National Health Fund-reimbursed costs of treatment of invasive cervical cancer in Poland in 2012.

Costs are presented in Polish Zloty (PLN). Diagnostic imaging examinations include: Doppler ultrasound examination, scintigraphy, computed tomography, magnetic resonance imaging, positron emission tomography, and single photon emission computed tomography.
To our knowledge, we present the first comprehensive report on the burden and associated costs of screening and management of HPV-related uterine cervical lesions in our country. Poland has implemented the National Cancer Registry (NCR) with regional bureaus which collect data on the incidence, mortality and morbidity due to invasive cancers. However, data on CIN burden are not available due to the lack of central registry of histological reports. Data on 773 cases of cervical carcinoma in situ reported for 2011 by the NCR are largely underestimated since registration of preinvasive lesions is uncommon. Our data, based on reports of women managed by the healthcare providers and reported to the NHF with ICD10 codes, indicate that the number of CIN3/ carcinoma in situ is probably more than 5 to 10 -fold higher than reported to the NCR. Over 6,000 cases were reported as CIN3/ carcinoma in situ and it is very likely that some proportion of over 36,000 cases coded as "unspecified CIN" are true CIN3/carcinoma in situ cases. According to our data there were 684 hysterectomies and 2,137 ablative or excision therapeutic procedures due to CIN3/carcinoma in situ. Our data are in concordance with the data from other countries with implemented cervical screening, which indicate that the incidence of CIN3/carcinoma in situ is several times higher than the incidence of invasive cancers (17). Annual number of women managed or suspected of preinvasive HPV-related cervical lesions is at the level of over 59,000. Most of these women are likely to be in the process of diagnosis or followup after treatment. Nevertheless, over 7,600 ablative or excision procedures such as: cryotherapy, diathermy, laser vaporisation, loop electrosurgical excision procedure (LEEP), large loop excision of the transformation zone (LLETZ), cold knife conisation or amputation of the uterine cervix and over 1,300 hysterectomies are performed annually in women with CIN/carcinoma in situ, which makes it a considerable public health problem in Poland.

The number of women with invasive cervical cancer treated within the NHF according to our analysis is over eleven times higher than the number of annual incident cases and three times as high as the number of annual prevalence reported by the NCR (18). This indicates that treatment, follow-up, rehabilitation, long-term and palliative care of women with invasive cervical cancer may take several years or longer and the procedures are reported with the ICD10 code C53 for treated patients. Some sort of miscoding by the healthcare providers is possible and the NHF data may overestimate the morbidity.

The total annual expenditures on organised screening of cervical lesions in Poland reached PLN 53.6 million in 2012, 22.6\% of which were spent for coordination, administration and logistics of the programme including postage of invitations to eligible women. The administrative costs are relatively high because of rather low cost of medical services due to the relatively low coverage rate of screening not exceeding $25 \%$.

Expenditures on opportunistic cervical screening, triage of abnormal pap results, diagnosis, treatment and follow-up of women with CIN equalled PLN 31.7 million and were smaller than costs of treatment of cervical glandular ectropion/erosion (PLN 37.3 million). Diagnosis and treatment of cervical glandular ectropion in Poland is very common and relatively costly despite the fact that this lesion is currently regarded as a physiological condition (19). It is also possible that services provided for collection and evaluation of opportunistic Pap smears and diagnostic procedures in CIN cases were erroneously coded with N86 code 
and therefore overvalued treatment of ectropion in Poland and undervalued costs of opportunistic screening and management of CIN. This may be due to the fact that in every-day gynaecological terminology in Poland, the term "erosion" is overused (and coded with N86 code) to describe any lesion on the cervix, regardless of its histological nature. Nevertheless, almost 40,000 ablative or excision therapeutic procedures were reimbursed for women with N86 diagnosis in 2012.

Expenditures on treatment of women with invasive cancer in 2012 were similar to costs of organised screening. The most expensive part of cancer management was radiotherapy.

Direct comparisons with other countries would not be correct due to differences in healthcare system organisation and socioeconomical conditions. Nevertheless, in Italy annual expenditure for cervical cancer screening and CIN treatment is estimated at EURO 2.94 per capita (17), which is over 4 times higher than in Poland. Different coverage of screening and pricing of procedures are most likely responsible for these differences.

The data provided by us are based on real expenditures of the Ministry of Health on screening administration and on real expenditures of the National Health Fund on medical procedures in screening and management of cervical neoplasia. However, our study has several limitations. Since there is no central country registry of pathology reports including CIN and any other pathological conditions, the numbers of incident CIN1, 2, 3 cases could only be estimated and the possibility that some patients were coded with different ICD10 codes and fall into groups of differing lesions could not be ruled out. Presented data are based on reports of all kinds of medical services provided to patients and coded with ICD10 classification. Therefore, they encompass women in the process of diagnosis, treatment and follow-up, rehabilitation and long-term/palliative care rather than the real prevalence or incidence of CIN and CC. It is also possible that presented costs of treatment of cervical ectropion/erosion include a part of expenditures on opportunistic screening reported to the NHF and coded with N86 code by care providers. Also, the study does not include out-of-pocket costs and indirect costs of screening and management of uterine cervical lesions because its perspective was the NHF - the only national public healthcare insurance institution. The expenditures in private healthcare sector are presumably considerable, especially for opportunistic screening.

To conclude, annually there are approximately 0.76 million and 1.28 million Pap smears performed in organised and reimbursed opportunistic cervical screening in Poland, respectively. Total medical and administrative costs of organised screening are estimated at over PLN 52 million. Annually, there are over 200,000, 59,000 and 33,000 of women suspected, treated or followed up due to cervical ectropion/erosion, CIN and CC within the NHFreimbursed healthcare in Poland, respectively. The total annual NHF expenditures for the management of cervical ectropion, CIN and CC were approximately PLN 37 million, 32 million and 52 million, respectively. In general, screening and management of HPV-related cervical lesions cost at least PLN 136 million from Polish public funds every year which makes them a considerable public health problem.

Our data on the costs of management of cervical glandular ectropion in Poland are alarming - although miscoding between N86 diagnosis and true preinvasive lesions (N87) is possible, overtreatment of benign glandular cervical ectropion which consumes huge NHF recourses is possible and should be looked into in details in further research. On the other hand, expenditures on rehabilitation of women with invasive $\mathrm{CC}$ are scarce, which suggests that this type of care is neglected in women with invasive $\mathrm{CC}$ and should be improved. There is an urgent need for an official registry of preinvasive lesions of the uterine cervix, which could provide high quality data on the burden of CIN based on histological reports in Poland.

\section{Conflict of Interests}

None declared

\section{Authors' Contributions}

AN conceived the study, analysed and interpreted the data and wrote the manuscript. AŚ and ZT organised obtaining the data for the manuscript. PS obtained the data for analysis. MC interpreted the data and suggested changes to the manuscript. All authors read, reviewed and approved the final manuscript.

\section{Ethical Considerations}

The use of data for this publication was approved by the National Health Fund (NHF) authorities. The data for this study were drawn collectively from NHF databases in a way which makes it impossible to reveal any personal details of patients.

\section{REFERENCES}

1. GLOBOCAN [Internet]. Lyon: IARC; 2016 [cited 2014 Nov 30]. Available from: http://globocan.iarc.fr/Pages/summary_table_pop_sel.aspx.

2. Bosch FX, Lorincz A, Muñoz N, Meijer CJ, Shah KV. The causal relation between human papillomavirus and cervical cancer. J Clin Pathol. 2002 Apr;55(4):244-65.

3. Markowitz LE, Tsu V, Deeks SL, Cubie H, Wang SA, Vicari AS, et al. Human papillomavirus vaccine introduction - the first five years. Vaccine. 2012 Nov 20;30 Suppl 5:F139-48.

4. Schiller JT, Castellsagué X, Garland SM. A review of clinical trials of human papillomavirus prophylactic vaccines. Vaccine. 2012 Nov 20;30 Suppl 5:F123-38.

5. Poljak M, Kocjan BJ. Commercially available assays for multiplex detection of alpha human papillomaviruses. Expert Rev Anti Infect Ther. 2010 Oct;8(10):1139-62.

6. EUCAN [Internet]. Lyon: IARC; 2012 [cited 2014 Dec 2]. Available from: http://eco.iarc.fr/eucan/CancerOne.aspx?Cancer=25\&Gender=2.

7. Nowakowski A, Jackowska T, Oszukowski PJ, Radowicki S, Wysocki J, Zatoński W. Prevention of cervical cancer - an interdisciplinary problem. Can we improve the situation in Poland and how? Pediatr Pol. 2013 Jul;88(4):340-6. (In Polish.)

8. State Sanitary Inspection [Internet]. Warsaw: Chief Sanitary Inspectorate; 2014 [cited 2014 May 5]. Immunization programme for Poland for 2014. Available from: http://www.gis.gov.pl/ckfinder/userfiles/files/ EP/informacje $\% 20 \mathrm{dla} \% 20$ podr $\% \mathrm{C} 3 \% \mathrm{~B} 3 \% \mathrm{C} 5 \% \mathrm{BCuj} \% \mathrm{C} 4 \% 85 \mathrm{cych} /$ PSO\%202014.pdf.

9. Vokó Z, Nagyjánosi L, Kaló Z. Cost-effectiveness of adding vaccination with the AS04-adjuvanted human papillomavirus 16/18 vaccine to cervical cancer screening in Hungary. BMC Public Health. 2012 Oct 30;12:924.

10. Obradovic M, Mrhar A, Kos M. Cost-effectiveness analysis of HPV vaccination alongside cervical cancer screening programme in Slovenia. Eur J Public Health. 2010 Aug;20(4):415-21.

11. Schobert D, Remy V, Schoeffski O. Cost-effectiveness of vaccination with a quadrivalent $\mathrm{HPV}$ vaccine in Germany using a dynamic transmission model. Health Econ Rev. 2012 Sep 25;2(1):19.

12. Seto K, Marra F, Raymakers A, Marra CA. The cost effectiveness of human papillomavirus vaccines: a systematic review. Drugs. 2012 Mar 26;72(5):715-43

13. Nahvijou A, Hadji M, Marnani AB, Tourang F, Bayat N, Weiderpass E, et al. A systematic review of economic aspects of cervical cancer screen- 
ing strategies worldwide: discrepancy between economic analysis and policymaking. Asian Pac J Cancer Prev. 2014;15(19):8229-37.

14. Ministry of Health [Internet]. Warsaw: Ministry of Health; 2015 [cited 2014 May 5]. Cervical Cancer Prevention Programme in Poland. Available from: http://www.mz.gov.pl/zdrowie-i-profilaktyka/programyzdrowotne/wykaz-programow/narodowy-program-zwalczania-chorobnowotworowych. (In Polish.)

15. Programme on Fight of Cancer in Poland [Internet]. Warsaw: Sejm of the Republic of Poland; 2013 [cited 2014 May 5]. Available from: http:// orka.sejm.gov.pl/Druki7ka.nsf/0/F78AF07990BD6AC5C1257B880040 846A/\%24File/1451.pdf. (In Polish.)

16. Pecorelli S, Zigliani L, Odicino F. Revised FIGO staging for carcinoma of the cervix. Int J Gynaecol Obstet. 2009 May;105(2):107-8.
17. Giorgi Rossi P, Ricciardi A, Cohet C, Palazzo F, Furnari G, Valle S, et al. Epidemiology and costs of cervical cancer screening and cervical dysplasia in Italy. BMC Public Health. 2009 Feb 25;9:71.

18. Polish National Cancer Registry [Internet]. Warsaw: Maria SklodowskaCurie Memorial Cancer Center and Institute; 2013 [cited 2014 Nov 22]. Available from: http://onkologia.org.pl. (In Polish.)

19. Machado Junior LC, Dalmaso AS, Carvalho HB. Evidence for benefits from treating cervical ectopy: literature review. Sao Paulo Med J. 2008 Mar 6;126(2):132-9.

Received March 8, 2015 Accepted in revised form May 12, 2016 